\title{
Lactation associated with a pituitary tumour in a man
}

\author{
T.M. Anoop MD, P.K. Jabbar MD DM, Joseph M. Pappachan MD MRCP
}

Previously published at www.cmaj.ca

A

26-year-old man presented with a one-year history of decreased libido and erectile dysfunction. He had no breast tenderness, but he had noticed a white discharge from his nipples after gentle manipulation (Figure 1). He had no history of visual abnormalities or headache and was not taking any medications or illicit drugs.

Examination showed gynecomastia and an absence of secondary sexual characteristics such as facial and body hair. Testicular volume was 10 (normal 12-25) mL. Examination of the visual field showed bitemporal hemianopia. Thyroid function was normal, as were other pituitary hormone levels (luteinizing, folliclestimulating, adrenocorticotropic and growth). The serum prolactin level was 13050 (normal 109-522) pmol/L, and the serum testosterone level 6.4 (normal 10.4-31.0) nmol/L. Magnetic resonance imaging showed a pituitary tumour measuring $2.2 \times 1.8 \times 1.2 \mathrm{~cm}$. After six months of treatment with bromocriptine, the patient's serum prolactin level had decreased to $609 \mathrm{pmol} / \mathrm{L}$, the serum testosterone level was normal $(12.0 \mathrm{nmol} / \mathrm{L})$, and the gonadal function was completely restored, as evidenced by normal libido and sexual activity. Magnetic resonance imaging six months later showed that the size of the pituitary tumour had decreased considerably.

Galactorrhea occurs in about $80 \%$ of women with prolactinomas but is uncommon in men with prolactinomas. Women with prolactinomas usually present with amenorrhea-galactorrhea syndrome and have pituitary microadenomas (measuring less than $1 \mathrm{~cm}$ ). In men, prolactinomas are usually macroadenomas (larger than $1 \mathrm{~cm}$ ), often associated with mass effects. Most prolactinomas can be managed with dopamine agonists and without pituitary surgery, and the prognosis is excellent. ${ }^{1,2}$

From the Department of Medicine (Anoop, Jabbar, Pappachan) and the Division of Endocrinology (Jabbar), Kottayam Medical College, Kerala, India
Experts recommend that patients with prolactinomas should be monitored yearly with measurement of serum prolactin levels and clinical assessment, and cautioned to seek medical help for any clinical signs of tumour growth, such as headaches or visual loss. ${ }^{1}$ Magnetic resonance imaging of the pituitary should be repeated if the serum prolactin levels are higher than $10875 \mathrm{pmol} / \mathrm{L}$. Magnetic resonance imaging should be repeated every two to three years in patients with macroadenomas. Pleural thickening, parenchymal lung disease and serosal fibrosis have been seen in patients treated long-term with high doses of dopamine agonists for Parkinson disease, but the risks appear to be negligible at the low doses for maintenance therapy of hyperprolactinemia. ${ }^{1}$ Surgical resection is reserved for people who cannot tolerate a dopamine agonist or in whom the drug is ineffective. ${ }^{3}$

This article has been peer reviewed.

Competing interests: None declared.

\section{REFERENCES}

1. Schlechte JA. Long-term management of prolactinomas. J Clin Endocrinol Metab 2007;92:2861-5

2. Melmed S. Update in pituitary disease. J Clin Endocrinol Metab 2008;93:331-8.

3. Casanueva FF, Molitch ME, Schlechte JA, et al. Guidelines of the Pituitary Society for the diagnosis and management of prolactinomas. Clin Endocrinol (Oxf) 2006;65:265-73. 